\title{
Word association analysis of children with disabilities
}

\author{
Sunhee Park \\ Department of Secondary Special Education, Daegu Haany University, Gyeongsan, Korea
}

Purpose: This study aimed to compare the types of response words for stimuli in children with language impairment and normal children through the word association task.

Methods: For this study, 60 children with language impairment aged 9-11 years old and 60 normal children of the same language age as them were selected. The list of stimulus words for the word association task consisted of 25 nouns, 6 verbs and 6 adjectives.

Results: The research results were as follows. First, it was found that the appearance rate of association words in the form and syntax among the intra-linguistic association was higher in the children with language impairment than in the normal children, and the appearance rate of association words in the meaning and pragmatics was lower than that of the normal children. Second, in children with language impairment, the appearance rate of verb response words was high in the noun stimulus words, and the noun response words appeared high in the verb and adjective stimulus words.

Conclusions: In conclusion, compared to the normal children, the form and syntax-oriented syntagmatic associative responses were higher than the semantic-oriented paradigmatic associative responses, indicating that the stimulus and response words were used side by side in sentences.

Keywords: Word association, Stimulus words, Syntagmatic association, Paradigmatic association

\section{INTRODUCTION}

Language is expressed through a complex process, and it is essential to produce it from an understanding lexicon. To produce such a language, vocabulary knowledge is an essential element. Vocabulary knowledge is closely related to overall linguistic ability, including semantic ability, and the meaning of words is also related in various ways. Use word associations as a method you can use to guess.

This word association task refers to a method of presenting a stimulus word, responding to the first word that immediately comes to mind, and analyzing the relationship according to the association factor between the stimulus word and the response word. The word association task serves as primary data for understanding the linguistic structure of a language, and by analyzing the associated response to a given word. It is possible to infer how learners construct and organize the word [1].

According to [2], in the association response, elementary school students generated more diverse associative words than college students, and college students were more convergent than elementary school students and had a typical word connection structure. In children, as age increases, noun-centered and language-centered associations

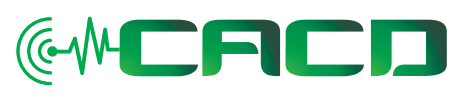

Received: August 3, 2021

Revision: August 30, 2021

Accepted: August 30, 2021

Correspondence:

Sunhee Park

Department of Secondary Special Education, Daegu Haany University, 1 Hanuidae-ro, Gyeongsan, Korea Tel: +82-53-819-1359 Fax: +82-53-819-1364 E-mail: ssun@dhu.ac.kr

(C) 2021 The Korean Association of SpeechLanguage Pathologists

This is an Open Access article distributed under the terms of the Creative Commons Attribution NonCommercial License (https://creativecommons.org/ licenses/by-nc/4.0/) which permits unrestricted noncommercial use, distribution, and reproduction in any medium, provided the original work is properly cited. 
decrease, and the degree of series association patterns with syntactic information added gradually increases. When elementary school students' associative response words were classified based on their frequency, the representative characteristic that appeared was the noun-centered association pattern [3]. As children reach school age, they increase their vocabulary and develop a qualitative vocabulary as their knowledge of words expands.

Children with language disabilities show deficits in meaning and have difficulties speaking, writing, and developing the general language knowledge necessary for school life [4]. In addition, the expressive word defects of children with language disabilities include fewer available words than normal children, lower level of name waiting, long response delay time, asymmetrical frequency of word-of-speech, and name waiting for errors. There is an impairment of the conceptual structure $[5,6]$. Some children with language impairments are good at naming pictures but may not be able to do specific language tasks such as using synonyms, using antonyms, defining words, employing words with different meanings, categorizing words into categories, and incorporating words into sentences.

An effective way to increase the vocabulary knowledge of these language-impaired children is to teach vocabulary and related vocabulary. Increasing vocabulary by considering lexical relationships such as synonyms, antonyms, hypernyms, and hyponyms or understanding vocabulary using the principle of vocabulary formation by exploring vocabulary formation through derivatives and compound words using productive suffixes and roots should also be observed. Children with language disabilities have many difficulties in vocabulary knowledge, even in academic performance and everyday communication. In addition, it is imperative to evaluate the qualitative knowledge of a specific word even if the lexical knowledge deficit is not prominent. A word association test is sometimes used for this qualitative evaluation.

The effectiveness of strategies using association as a vocabulary instruction method for children with language disabilities is mentioned. In this study, we present primary data for understanding the linguistic structure of children with language disabilities by examining the reaction patterns of children with language impairments through the word association task and comparing them with the children in the sample group. In addition, the significance of this study is to reveal strategies that are helpful for vocabulary education on the semantic structure and vocabulary knowledge guidance of chil- dren with language disabilities through these primary data.

\section{METHODS}

\section{Research subject}

A total of 60 children were selected, with 10 male and feale children with language impairment for each age group of 9 to 11 years of age. A total of 120 children were selected, with a total of 60 children, having 10 males and females of the same language age.

\section{Children with language impairment}

First were children with language impairment or whose receptive vocabulary age was 9 to 11 years old based on the Receptive Expressive Vocabulary Test (REVT) [7]. Second were children who did not have any other physical disabilities, such as emotional and behavioral problems, as reported by their parents or homeroom teachers, were chosen. Third, in the case of children with speech disabilities, children enrolled in special schools and special classes who had no experience in speech therapy outside of school classes were selected.

\section{Normal children}

For normal children, first, children between the ages of 9 and 11 who were enrolled in grades 3 to 5 of elementary school were selected. Second, children with more than -1 SD based on the REVT results were chosen. Third, children who were reported to have no language ability, cognition, behavior, emotion, hearing, or temperament problems by their teachers and parents were selected (Table 1).

\section{Research tool}

For word selection for word association test, the preliminary list was collected based on the criteria of the previous study $[8,9]$, which consisted of a vocabulary with a high frequency of use, a vocabulary with a wide range of use, a vocabulary based on education, and a vocabulary suitable for the developmen-

Table 1. Specific information of participants

\begin{tabular}{lcr}
\hline & $\begin{array}{c}\text { Children with } \\
\text { language } \\
\text { impairment } \\
(\mathrm{N}=60)\end{array}$ & $\begin{array}{c}\text { Normal } \\
\text { children } \\
(\mathrm{N}=60)\end{array}$ \\
\hline $\begin{array}{l}\text { Chronological age M (SD) } \\
\text { Receptive language age (months) } \\
\mathrm{M}(\mathrm{SD})\end{array}$ & $15.6(2.2)$ & $10.1(0.8)$ \\
\hline
\end{tabular}


tal stage of the learner. Afterward, 15 nouns and 7 words each for verbs and adjectives were selected by referring to data from the word association study [10-12]. Among them, a total of 25 stimuli were selected as the final stimulus words: 13 nouns, 6 verbs, and 6 adjectives (Table 2).

\section{Research procedure}

Before the practice test and the primary test, the test's purpose was explained to the parents and children with language impairment and normal children. The test was conducted 1:1

Table 2. The list of word stimuli

\begin{tabular}{llll}
\hline Noun & & Verb & Adjective \\
\hline Dog & Friend & Give & Pretty \\
Father & Head & Make & Difficult \\
Money & House & Eat & Sick \\
Sun & Face & Wear & Heavy \\
Flower & Study & Hit & Sad \\
Song & Love & Cut & Clean \\
Water & & & \\
\hline
\end{tabular}

Table 3. Associations and examples of stimulus words and associative words

\begin{tabular}{|c|c|c|c|c|}
\hline \multicolumn{3}{|c|}{ Association factor } & Contents & \multirow{2}{*}{$\frac{\text { Example }}{\text { Rain-rain (singer) }}$} \\
\hline Intra-linguistic & Form & Phonology & When the sound image of a stimulus word becomes a language element & \\
\hline & & Morphology & A change of word class or conjugation of a stimulus word & Eat-ate \\
\hline & Syntax & Subject-predicate & When a stimulus word has a subject or predicate relationship & Banana-eat \\
\hline & & Object-predicate & $\begin{array}{l}\text { Words that have a relationship between a stimulus and an object or } \\
\text { predicate }\end{array}$ & Shoes-wear \\
\hline & & Adverb-predicate & $\begin{array}{l}\text { Words that have a relationship between a stimulus and an adverb or } \\
\text { predicate }\end{array}$ & Scissors-cut \\
\hline & Meaning & Aynonym & Words similar to stimuli word & Father-dad \\
\hline & & Antonym & Opposite word for stimulus word & Dad-mom \\
\hline & & Hypernym & Words that higher range of containing stimuli word & Dog-animal \\
\hline & & Hyponym & Words with lower range and containing stimuli word & Flower-rose \\
\hline & & Symbol & An abstract idea or symbol raised by a stimulus word & Love- $\varnothing$ \\
\hline & Pragmatics & & Words made up of conversational responses to stimuli & Pretty-thank you \\
\hline \multirow[t]{7}{*}{ Extra-linguistic } & Similarity & Attributes of stimulus word & Attributes of stimulus word & Candy-sweet \\
\hline & & Allowed attributes & Attributes that are socially acceptable to have similarities to stimuli word & Life-marathon \\
\hline & & Individual properties & $\begin{array}{l}\text { Recognized and socially unacceptable attributes limited to older people and } \\
\text { individuals }\end{array}$ & Sea-daughter \\
\hline & Adjacency & Part-whole & $\begin{array}{l}\text { Relationship between the stimuli and the associations between the whole } \\
\text { and its parts }\end{array}$ & Dog-tail \\
\hline & & Time & Association by temporal proximity & Rose-may \\
\hline & & Space & Association by spatial proximity & Eat-restaurant \\
\hline & & Causality & Stimulus and associative words indicate a causal relationship & Hit-hurts \\
\hline
\end{tabular}

between the child and the examiner in a quiet space, and the examiner and the child sat facing each other at a desk to form a rapport. When the examiner heard one stimulus word to the child, the child was asked to respond with one word as quickly as possible to the first thing that came to mind after hearing the presented stimulus word.

\section{Data analysis}

The association criteria were revised and supplemented by the researcher based on previous studies [11,12]. Table 3 below shows associative factors and explanations and examples of associative relationships between stimuli and associative words.

The prevalence rate of the types of associated response words among the target children was calculated as the percentage of each response type with respect to the total frequency of occurrence after summing the frequencies of each child's associative responses.

\section{Reliability}

The reliability of the evaluation was calculated through the in- 
ter-rater reliability for the response type. The concordance rate was examined by analyzing $30 \%$ of the data randomly extracted from the total data of the target children together with a researcher and a person with a level 2 qualification as a speech therapist with more than 3 years of experience. As a result, the concordance rate was $97 \%$ for the whole stimulus word, $98 \%$ for the noun stimulus word, $96 \%$ for the verb stimulus word, and $96 \%$ for the adjective stimulus word.

\section{Statistical analysis}

An independent sample T-test was performed to compare the appearance rates of association word types according to stimulus words between the two groups of children with language impairment and children with generalized language. At this time, the data were analyzed using the SPSS 27.0 program.

\section{RESULTS}

\section{Association of children with language impairment and normal children by association factors}

\section{Intra-linguistic associative response type}

In the form and syntax of the children with language impairment and the normal children, the appearance rate of association words of the children with language impairment was high, which was found to be statistically significant. Also, in terms of meaning and pragmatics, the appearance rate of association words was high in normal children, indicating that children with language impairment produced statistically sig-

Table 4. Comparison of associative language response types of intra-linguistic factors in children with language impairment and normal children

\begin{tabular}{llccc}
\hline \multicolumn{2}{l}{ Association factor } & $\begin{array}{c}\text { Children with } \\
\text { language } \\
\text { impairment } \\
\text { M (SD) }\end{array}$ & $\begin{array}{c}\text { Normal } \\
\text { children } \\
\text { M (SD) }\end{array}$ & $t$ \\
\hline Form & Phonology & $0.7(2.2)$ & $0.1(0.7)$ & $1.951^{* *}$ \\
Syntax & Morphology & $3.1(9.4)$ & $1.3(2.6)$ & $1.436^{* *}$ \\
& Subject-Predicate & $30.3(13.1)$ & $15.2(9.4)$ & $7.282^{* *}$ \\
& Object-Predicate & $25.9(12.3)$ & $12.1(6.7)$ & $7.608^{* *}$ \\
Meaning & Adverb-Predicate & $7.3(8.8)$ & $3.23(3.8)$ & $3.294^{* *}$ \\
& Synonym & $2.4(3.7)$ & $6.0(6.0)$ & $-3.933^{*}$ \\
& Antonym & $1.8(4.2)$ & $3.9(10.1)$ & $-1.461^{*}$ \\
& Hypernym & $1.0(1.9)$ & $3.9(5.6)$ & $-3.853^{* *}$ \\
& Hyponym & $7.1(7.6)$ & $7.6(5.0)$ & $-0.393^{* *}$ \\
& Symbolic & $3.5(6.5)$ & $5.7(7.3)$ & $-1.803^{*}$ \\
\hline \multirow{2}{*}{ Pragmatics } & $0.2(0.9)$ & $1.8(3.2)$ & $-3.930^{* *}$ \\
\hline
\end{tabular}

nificantly lower association words than normal children. In addition, it was found that children with language impairment showed a statistically significantly lower prevalence of associations in pragmatics than normal children.

Table 4 compares and presents associative language response types of intra-linguistic factors in children with language impairment and normal children.

\section{Extra-linguistic associative response type}

Upon comparing the similarity and adjacency between children with language impairment and normal children, children with language impairment showed a lower rate of association of words compared to normal children in both association factors. Among the similarities, it was interpreted that the children with language impairment showed statistically significantly lower association words compared to the normal children in the part-whole, space, and causality in the attributes of stimulus word, allowed attributes and adjacency areas.

Table 5 compares and presents associative language response types of extra-linguistic factors in children with language impairment and normal children.

\section{Associated language word-class types of children with speech disabilities}

It was found that children with language impairment produced lower association words for nouns, adjectives, and others compared to normal children; in particular, they showed statistically significantly lower output in others. Also, in verbs and adverbs, it was found that children with language impairment showed a higher incidence of associations than normal children and statistically significantly higher associations in verbs.

Table 5. Comparison of associative language response types of extra-linguistic factors in children with language impairment and normal children

\begin{tabular}{|c|c|c|c|c|}
\hline \multicolumn{2}{|c|}{ Association factor } & \multirow{2}{*}{$\begin{array}{c}\text { Children with } \\
\text { language } \\
\text { impairment } \\
\text { M (SD) } \\
0.9(2.3)\end{array}$} & \multirow{2}{*}{$\begin{array}{c}\text { Normal } \\
\text { children } \\
\mathrm{M}(\mathrm{SD})\end{array}$} & \multirow{2}{*}{$\begin{array}{c}t \\
-8.416^{* *}\end{array}$} \\
\hline Similarity & $\begin{array}{l}\text { Attributes of stimulus } \\
\text { word }\end{array}$ & & & \\
\hline & Allowed attributes & $8.5(7.3)$ & $18.3(10.0)$ & $-6.093^{*}$ \\
\hline & Individual properties & $3.0(4.1)$ & $3.1(4.5)$ & -0.085 \\
\hline \multirow[t]{4}{*}{ Adjacency } & Part-whole & $0.2(1.1)$ & $0.5(1.3)$ & $-1.194^{*}$ \\
\hline & Time & $0.1(0.7)$ & $0.2(0.9)$ & -0.453 \\
\hline & Space & $1.6(3.2)$ & $4.2(5.3)$ & $-3.254^{* *}$ \\
\hline & Causality & $1.3(2.8)$ & $8.4(9.5)$ & $-5.505^{* *}$ \\
\hline
\end{tabular}


Table 6 compares and presents associative language wors class types in children with language impairment and normal children.

\section{Children with language impairment and normal children respond to association according to stimuli word-for-word class}

\section{Associative response types to noun stimuli word}

Associative response types of intra-linguistic association factors In the form and syntax of the children with language impairment and the normal children, the prevalence of association words of the children with language impairment was high, and it was found that this was statistically significant. In terms of meaning, it was found that the occurrence rate of association words was high in synonym, hypernym, hyponym, and symbol of normal children, while children with language impairment produced statistically significantly lower association words than normal children. In addition, it was found that children with language impairment showed a statistically significantly lower prevalence of associations in pragmatics than normal children.

Table 7 compares and presents associative response types of intra-linguistic factors to noun stimuli word.

\section{Associative response types of extra-linguistic association factors} In the similarity between children with language impairment and normal children, it was found that children with language impairment produced statistically significantly lower association words than normal children in the attributes of stimulus word. Also, in adjacency, it was found that children with language impairment showed a statistically significantly lower rate of association in time and space compared to these normal children.

Table 8 compares and presents associative response types

Table 6. Comparison of Associated Language word class types of children with language impairment and normal children

\begin{tabular}{lccc}
\hline Word class & $\begin{array}{c}\text { Children with } \\
\text { language } \\
\text { impairment } \\
\text { M (SD) }\end{array}$ & $\begin{array}{c}\text { Normal } \\
\text { children } \\
\text { M (SD) }\end{array}$ & $t$ \\
\hline Noun & $70.1(22.3)$ & $73.7(20.1)$ & -0.915 \\
Verb & $13.0(13.1)$ & $7.6(7.9)$ & $2.728^{* *}$ \\
Adjective & $12.6(12.5)$ & $15.7(14.1)$ & -1.286 \\
Adverb & $0.8(2.3)$ & $0.7(2.6)$ & 0.149 \\
Other & $0.3(1.0)$ & $0.9(2.9)$ & $-1.571^{* *}$ \\
\hline
\end{tabular}

of extra-linguistic factors to noun stimuli word.

Types of word class for children with language impairment and normal children for noun stimulus words

Children with language impairment showed a lower incidence of association words in nouns, adjectives, and other word classes than normal children, and statistically significant results in nouns and others compared to normal children. Also, in verbs and adverbs, it was found that children with language impairment showed statistically significantly higher association words than normal children.

Table 9 compares and presents associative response types by word class to noun stimuli word.

Table 7. Comparison of associative response types of intra-linguistic factors to noun stimuli word

\begin{tabular}{llccc}
\hline Association factor & $\begin{array}{c}\text { Children with } \\
\text { language } \\
\text { impairment } \\
\text { M (SD) }\end{array}$ & $\begin{array}{c}\text { Normal } \\
\text { children } \\
\text { M (SD) }\end{array}$ & $t$ \\
\hline Form & Phonology & $1.3(4.30)$ & $0.3(1.4)$ & $1.764^{* *}$ \\
Syntax & Morphology & $4.8(11.5)$ & $0.6(3.3)$ & $2.638^{* *}$ \\
& Subject-Predicate & $28.3(20.8)$ & $11.7(14.5)$ & $5.095^{* *}$ \\
& Object-Predicate & $1.9(2.1)$ & $0.4(1.1)$ & $5.211^{* *}$ \\
Meaning & Adverb-Predicate & $5.1(9.1)$ & $0.6(2.7)$ & $3.620^{* *}$ \\
& Synonym & $1.9(4.6)$ & $7.4(8.1)$ & $-4.554^{* *}$ \\
& Antonym & $1.5(4.2)$ & $1.9(5.6)$ & $-0.522^{*}$ \\
& Hypernym & $2.1(3.9)$ & $6.3(7.2)$ & $-4.006^{* *}$ \\
& Hyponym & $13.1(14.9)$ & $14.4(11.3)$ & $-0.551^{*}$ \\
& Symbol & $1.9(3.9)$ & $3.7(5.7)$ & $-1.991^{* *}$ \\
\hline \multirow{2}{*}{ Pragmatics } & & $0.1(0.9)$ & $0.5(2.4)$ & -1.148 \\
\hline
\end{tabular}

Table 8. Comparison of associational response types of extra-linguistic association factors to noun stimuli word

\begin{tabular}{|c|c|c|c|c|}
\hline \multicolumn{2}{|c|}{ Association factor } & \multirow{2}{*}{$\begin{array}{c}\begin{array}{c}\text { Children with } \\
\text { language } \\
\text { impairment } \\
\mathrm{M}(\mathrm{SD})\end{array} \\
0.5(3.1)\end{array}$} & \multirow{2}{*}{$\begin{array}{l}\text { Normal } \\
\text { children } \\
\text { M (SD) }\end{array}$} & \multirow{2}{*}{$\begin{array}{c}t \\
-6.588^{* *}\end{array}$} \\
\hline Similarity & $\begin{array}{l}\text { Attributes of } \\
\text { stimulus word }\end{array}$ & & & \\
\hline & Allowed attributes & $13.6(14.1)$ & $28.1(15.1)$ & -5.440 \\
\hline & Individual properties & $4.3(7.1)$ & $4.2(6.3)$ & 0.043 \\
\hline \multirow[t]{4}{*}{ Adjacency } & Part-Whole & $0.6(3.3)$ & $0.89(2.5)$ & -0.484 \\
\hline & Time & $0.1(0.9)$ & $0.4(1.7)$ & $-1.013^{*}$ \\
\hline & Space & $2.1(4.5)$ & $5.8(8.3)$ & $3.049^{* *}$ \\
\hline & Causal & $0.2(1.4)$ & $1.4(9.0)$ & -0.980 \\
\hline
\end{tabular}


Table 9. Comparison of associative response types by word class to noun stimuli word

\begin{tabular}{lccc}
\hline Word class & $\begin{array}{c}\text { Children with } \\
\text { language } \\
\text { impairment } \\
\text { M (SD) }\end{array}$ & $\begin{array}{c}\text { Normal } \\
\text { children } \\
\text { M (SD) }\end{array}$ & $t$ \\
\hline Noun & $61.0(29.1)$ & $75.7(22.1)$ & $-3.114^{*}$ \\
Verb & $20.1(21.2)$ & $5.1(7.9)$ & $5.120^{* *}$ \\
Adjective & $14.0(15.1)$ & $16.2(15.5)$ & -0.538 \\
Adverb & $7.1(14.9)$ & $1.3(5.3)$ & $2.845^{* *}$ \\
Other & $0.3(1.4)$ & $1.2(3.1)$ & $-2.040^{* *}$ \\
\hline
\end{tabular}

\section{Associative response types to verb stimuli word}

Associative response types of intra-linguistic association factors

Upon comparing the children with language disabilities and the general children, it was found that the children with language disabilities showed a higher rate of appearance of associations in form and syntax and lower than that of ordinary children in meaning. Children with language impairment showed a statistically and meaningfully higher result than normal children in the adverb-descriptive words of the phrase. They also showed a statistically significantly lower incidence of association words in the synonym, antonym, symbol, and pragmatics in meaning than normal children.

Table 10 compares and presents associative response types of intra-linguistc factors to noun stimuli word.

\section{Associative response types of extra-linguistic association}

\section{factors}

Compared with the similarity between the children with language impairment and the normal children, it was found that the children with language impairment produced statistically significantly lower association words than the typical children in the attributes of stimulus word and allowed attributes. Also, in adjacency, children with language impairment showed a statistically significantly lower rate of association of words than normal children.

Table 11 compares and presents associative response types of extra-linguistc factors to verb stimuli word.

Types of word class for children with language impairment and normal children for verb stimulus words

Upon comparing the two groups, the children with language impairment showed statistically significantly higher association words in nouns than the normal children.
Table 10. Comparison of associative response types of intra linguistic factors to verb stimuli word

\begin{tabular}{llccc}
\hline Association factor & $\begin{array}{c}\text { Children with } \\
\text { language } \\
\text { impairment } \\
\text { M (SD) }\end{array}$ & $\begin{array}{c}\text { Normal } \\
\text { children } \\
\text { M (SD) }\end{array}$ & $t$ \\
\hline Form & Morphology & $2.5(13.6)$ & $1.9(5.4)$ & 0.291 \\
Syntax & Subject-predicate & $4.2(14.3)$ & $5.0(14.5)$ & -0.317 \\
& Object-predicate & $61.5(33.2)$ & $42.1(26.2)$ & 3.554 \\
& Adverb-predicate & $18.9(29.2)$ & $10.5(13.8)$ & $1.982^{* *}$ \\
Meaning & Synonym & $1.9(5.4)$ & $4.2(10.9)$ & $-1.414^{* *}$ \\
& Antonym & $0.6(3.0)$ & $3.9(11.2)$ & $-2.223^{* *}$ \\
& Hypernym & $0.0(0)$ & $0.0(0)$ & - \\
& Hyponym & $0.6(4.3)$ & $0.0(0)$ & $1.000^{*}$ \\
& Symbol & $0.0(0)$ & $1.7(7.3)$ & $-1.763^{* *}$ \\
\hline \multirow{2}{*}{ Pragmatics } & & $0.3(2.2)$ & $3.6(9.4)$ & $-2.587^{* *}$ \\
\hline
\end{tabular}

Table 11. Comparison of associational response types of extra-linguistic association factors to verb stimuli word

\begin{tabular}{|c|c|c|c|c|}
\hline Associatic & on factor & $\begin{array}{l}\text { Children with } \\
\text { language } \\
\text { imnairment }\end{array}$ & $\begin{array}{l}\text { Normal } \\
\text { children }\end{array}$ & $t$ \\
\hline Similarity & $\begin{array}{l}\text { Attributes of stimulus } \\
\text { word }\end{array}$ & $0.3(2.2)$ & $1.9(7.6)$ & $-1.640 * *$ \\
\hline & Allowed attributes & $0.3(2.2)$ & $7.8(14.2)$ & $-4.042^{* *}$ \\
\hline & Individual properties & $0.6(3.0)$ & $0.3(2.2)$ & 0.581 \\
\hline Adjacency & Part-Whole & $0.3(2.2)$ & $0.8(4.8)$ & -0.820 \\
\hline & Time & $2.5(8.6)$ & $15.0(22.3)$ & $-4.058^{* *}$ \\
\hline
\end{tabular}

Table 12 compares and presents associative response types by word class to verb stimuli word.

\section{Associative response types to adjective stimulus words}

Associative response types of intra-linguistic association factors

Upon comparing the children with language impairment and the normal children, the children with language impairment showed statistically significantly lower results than the typical children in sound and phonology. In terms of syntax, children with language impairment produced statistically significantly higher association words than normal children in subjectpredicate, object-predicate, and adverb-predicate. In terms of meaning, it was found that children with language impairment produced associated words that were statistically and meaningfully lower than that of normal children, with the oc- 
Table 12. Comparison of associative response types by word class to verb stimuli word

\begin{tabular}{lccc}
\hline Word class & $\begin{array}{c}\text { Children with } \\
\text { language } \\
\text { impairment } \\
\mathrm{M}(\mathrm{SD})\end{array}$ & $\begin{array}{c}\text { Normal } \\
\text { children } \\
\mathrm{M}(\mathrm{SD})\end{array}$ & $t$ \\
\hline Noun & $90.56(20.4)$ & $74.9(29.0)$ & $3.395^{* *}$ \\
Verb & $2.8(11.1)$ & $8.9(16.1)$ & $-2.428^{* *}$ \\
Adjective & $1.7(5.9)$ & $11.2(22.8)$ & $-3.146^{* *}$ \\
Adverb & $0.8(3.7)$ & $1.1(6.7)$ & -0.278 \\
Other & $0.0(0)$ & $0.3(2.2)$ & $-1.000^{*}$ \\
\hline
\end{tabular}

Table 13. Comparison of associative response types of intra linguistic factors to adjective stimulus words

\begin{tabular}{llccc}
\hline Association factor & $\begin{array}{c}\text { Children with } \\
\text { language } \\
\text { impairment } \\
\text { M (SD) }\end{array}$ & $\begin{array}{c}\text { Normal } \\
\text { children } \\
\text { M (SD) }\end{array}$ & $t$ \\
\hline Form & Phonology & $0.0(0)$ & $0.3(2.2)$ & $-1.000^{*}$ \\
\multirow{5}{*}{ Syntax } & Morphology & $1.9(9.3)$ & $0.8(4.8)$ & 0.828 \\
& Subject-Predicate & $63.9(29.4)$ & $35.6(21.6)$ & $9.023^{*}$ \\
& Object-Predicate & $5.3(12.5)$ & $1.4(7.1)$ & $2.214^{* *}$ \\
Meaning & Adverb-Predicate & $4.5(8.0)$ & $1.4(8.8)$ & $2.007^{* *}$ \\
& Synonym & $2.5(8.0)$ & $3.9(9.4)$ & -0.871 \\
& Antonym & $3.3(13.6)$ & $3.6(15.4)$ & -0.106 \\
& Hypernym & $0.0(0)$ & $0.5(3.0)$ & $-1.426^{* *}$ \\
& Hyponym & $0.3(2.2)$ & $0.0(0.1)$ & 0.938 \\
& Symbol & $0.3(2.2)$ & $1.9(8.2)$ & $-1.528^{* *}$ \\
\hline \multirow{2}{*}{ Pragmatics } & & $0.3(2.2)$ & $2.2(5.7)$ & $-2.467^{* *}$ \\
\hline
\end{tabular}

currence rate of association words in the hypernym and symbol of ordinary children. In addition, it was found that children with language impairment showed a statistically significantly lower prevalence of associations in pragmatics than normal children.

Table 13 compares and presents associative response types of intra-linguistic factors to adjective stimuli word.

\section{Associative response types of extra-linguistic association factors}

Upon comparing children with language impairment and normal children, it was found that children with language impairment produced statistically significantly lower association words than normal children in all factors of similarity. Also, in terms of proximity, it was found that children with language impairment showed a statistically significantly lower rate of
Table 14. Comparison of associative response types of extra-linguistic factors to adjective stimulus words

\begin{tabular}{ccccc}
\hline Association factor & $\begin{array}{c}\text { Children with } \\
\text { language } \\
\text { impairment } \\
\text { M (SD) }\end{array}$ & $\begin{array}{c}\text { Normal } \\
\text { children } \\
\mathrm{M}(\mathrm{SD})\end{array}$ & $t$ \\
\hline Similarity & $\begin{array}{c}\text { Attributes of } \\
\text { stimulus word }\end{array}$ & $2.5(6.01)$ & $10.9(10.9)$ & $-5.253^{* *}$ \\
& & & \\
& Allowed attributes & $5.8(11.4)$ & $11.7(16.0)$ & $-2.298^{* *}$ \\
& Individual & $0.8(3.7)$ & $2.5(6.7)$ & $-1.638^{* *}$ \\
properties & & & \\
Adjacency & $\begin{array}{c}\text { Part-Whole } \\
\text { Time }\end{array}$ & $0.3(2.2)$ & $0.0(0)$ & $1.000^{*}$ \\
& $0.3(2.1)$ & $3.1(7.2)$ & $-2.867^{* *}$ \\
Space & $3.3(6.7)$ & $18.1(22.2)$ & $-4.917^{* *}$ \\
\hline
\end{tabular}

Table 15. Comparison of associative response types by word class to adjective stimulus words

\begin{tabular}{lccc}
\hline Word class & $\begin{array}{c}\text { Children with } \\
\text { language } \\
\text { impairment } \\
\mathrm{M}(\mathrm{SD})\end{array}$ & $\begin{array}{c}\text { Normal } \\
\text { children } \\
\mathrm{M}(\mathrm{SD})\end{array}$ & $t$ \\
\hline Noun & $84.4(25.7)$ & $71.4(28.5)$ & 2.626 \\
Verb & $6.9(13.5)$ & $12.8(13.8)$ & -2.340 \\
Adjective & $7.8(19.9)$ & $12.3(22.1)$ & -1.161 \\
Adverb & $1.7(6.6)$ & $0.6(3.0)$ & $1.195^{*}$ \\
Other & $0.3(2.1)$ & $1.1(5.2)$ & $-1.148^{*}$ \\
\hline
\end{tabular}

occurrence of association words in time, space, and causality than normal children.

Table 14 compares and presents associative response types of extra-linguistic factors to adjective stimuli word.

Types of word class of children with language impairment and normal children for adjective stimulus words

It was found that the children with language impairment showed statistically significantly lower association words in other.

Table 15 compares and presents associative response types by word class to adjective stimuli word.

\section{DISCUSSION}

These research methods and procedures were discussed according to the results of other studies.

First, it was found that the appearance rate of association words in the form and syntax among the intra-linguistic association factors was higher in the children with language im- 
pairment than in the normal children, and the appearance rate of association words in the meaning and pragmatics was lower than that of the normal children. This was interpreted that the children with language impairment had higher associations between form and syntax than those of normal children and that the series associations meaning were lower than those of normal children. Syntagmatic associations have sub-elements of form and syntax in which the stimulus and response words are used side by side in a sentence. Paradigmatic association includes meanings and the like as two words are used as synonyms, antonyms, and hypernyms. The results of this study showed that, compared to children, the series response was mainly selected for word association in adults, it is similar to the study result of Kim [6], who showed a transitional tendency of association from a binding reaction to a series reaction around the age of 5 to 9 years.

Second, the types of association words according to the stimuli for each word class were compared with the children with language impairment. First of all, in the pronoun stimuli word, the children with language impairment showed a higher output rate in the form and syntax among the intra-linguistic association factors than the average children, so the association was more than the semantic series association centered on the meaning. Regarding the similarity and adjacency of extra-linguistic association factors, children with language impairment showed a lower prevalence than normal children. Next, in the verb stimulus word, the combinational association of form and syntax showed a higher rate of occurrence than the serial association of meaning. As for the similarity and adjacency of extra-linguistic association factors, children with language impairment showed a lower prevalence than normal children. In the adjective stimulus words, the children with language impairment showed a higher output rate for the combinational association of form and syntax than the serial association of meaning. Both similarity and adjacency showed a lower prevalence rate in children with language impairment than normal children. In the word association task, it was reported that there were differences in response types depending on the word class of the stimulus word, and since nouns are less abstract than verbs and adjectives, there are many semantic-based response types $[1,12,13]$. Verbs and adjectives often show associative words that express feelings or states brought about by an action and associations that can establish the syntactic frame of sentences in which verbs or adjectives are used mainly appear. For this reason, unlike noun stimuli, which showed high associations outside of language, intra-linguistic associations were predominant in associations with verbs and adjectives [11]. Verbs showed longer syntagmatic associations than nouns, and in adults, the response to adjectives appears as series associations $[6,14]$.

The purpose of this study was to compare and examine the types of response words for stimuli in children with language impairment and normal children through the word association task. Although age and gender considerations were not discussed, the study subjects were selected as 9-11 years old, and it is hoped that future studies will continue to study associational responses to age and gender. In addition, it is expected that the research will be conducted by including considerations according to age and gender to provoke words of nouns, adjectives, and verbs.

\section{ACKNOWLEDGMENTS}

This research is a result of sabbatical year granted by Daegu Haany University Kylin Foundation in 2018.

\section{REFERENCES}

1. Lee YS, Kim JS. Lexical-semantic organization in students with hearing impairments. The Journal of Special Education: Theory and Practice. 2012;13:129-151.

2. Park M. Comparison of word association between adults and children. Korean Journal of Cognitive Science. 2008;19:17-39.

3. Lim JH. Study of English vocabulary learning through word association (Master's thesis). Yonsei University; 2002.

4. Shin MJ, Lee HR. Word associations and semantic absurdities detection of school aged children with specific language impairment. Journal of Speech-Language \& Hearing Disorders. 2016;25: 37-45.

5. Aram DM, Nation JE. Child language disorders. St. Louis, MO: C. V. Mosby; 1982.

6. Kim MS. Comparison of Word Association between Normal Children and Language- Delayed Children (Master's thesis). Dankook University; 2004.

7. Kim YT, Hong GH, Kim KH, Jang HS, Lee JY. Receptive \& expressive vocabulary test (REVT). Seoul: Seoul Community Rehabilitation Center; 2011.

8. Kim EJ. Affectivity examination to develop the Word Association Test for Children and Adolescents (Master's thesis). Hanyang University; 2009.

9. Lee NN. Characteristics of Noun Definition in School-aged Children with Mild Intellectual Disability (Master's thesis). Dankook University; 2014.

10. Choi SY. Association norms of word association test to child and 
adolescence (Master's thesis). Hanyang University; 2009.

11. Kim EH. A study on meaning focused korean vocabulary education with word association -for advanced korean learners- (Doctoral dissertation). Inha University; 2012.

12. Jwa AY. A comparison in the characteristics of lexical-semantic organization between children with specific language impairment and normal children through a word association task (Master's thesis). Dankook University; 2015.

13. Kang SS. Lexical-semantic organization in Korean EFL Learners: Evidence from an L2 and corresponding L1 word association test (Master's thesis). Korea National University of Education, Chungbuk; 2011.

14. Nelson. Event Knowledge: Structure and function in development. Hillsdale, NJ: Erlbaum; 1986. 